\title{
PENERAPAN TEKNIK DISPUTE COGNITIVE DALAM REBT UNTUK MENINGKATKAN RESILIENSI PADA MAHASISWA (Single Subject Research terhadap mahasiswa Program Studi Psikologi Angkatan 2014 Fakultas Ilmu Pendidikan Universitas Negeri Jakarta)
}

\author{
Novi Fitriani ${ }^{1}$ \\ Eka Wahyuni² \\ Happy Karlina Marjo ${ }^{3}$
}

\begin{abstract}
Abstrak
Artikel ini bertujuan untuk mengetahui pengaruh penerapan teknik dispute cognitive terhadap peningkatan resiliensi. Sampel dalam penelitian ini adalah mahasiswa jurusan Psikologi 2014 sebanyak satu orang yang berinisial FDP. Pengambilan sampel menggunakan teknik purposive sampling yaitu responden diambil dengan pertimbangan dan tujuan tertentu yaitu memiliki resiliensi rendah Penelitian menggunakan pendekatan kuantitatif dengan metode yang digunakan adalah Single Subject Research dengan menggunakan desain A-B, dimana A adalah kondisi baseline yang belum diberikan intervensi, dan B kondisi intervensi dengan teknik dispute cognitive yang diberikan kepada mahasiswa yang memiliki resiliensi rendah. Instrumen penelitian yang digunakan adalah Skala Resiliensi. Hasil penelitian menunjukkan intervensi pendekatan Rational Emotive Behavioral Therapy (REBT) dengan menggunakan teknik Dispute Cognitive dapat meningkatkan resiliensi. Terbukti dari skor resiliensi FDP mengalami peningkatan setelah diberikan intervensi sebesar 201 dalam kategori sedang dibandingkan sebelum adanya intervensi dengan skor 170 dalam kategori rendah.
\end{abstract}

Kata Kunci : Pendekatan REBT, Teknik Dispute Cognitve, Resiliensi

\section{PENDAHULUAN}

Kemampuan setiap mahasiswa dalamkesiapan untuk menghadapi tantangan pasti berbeda. Perbedaan kesiapan mahasiswa dalam menghadapi tantangan ternyata disebabkan oleh cara pandang yang berbeda terhadap permasalahan yang ada. Salah satu faktor perbedaan itu adalah resiliensi.

Reivich dan Shatté (2002) mengatakan resiliensi adalah kemampuan untuk bertahan dan beradaptasi terhadap peristiwa yang berat atau masalah yang terjadi dalam kehidupan. Hasil penelitian Grotberg (1999) mengatakan resiliensi sangat penting dalam membantu individu untuk mengatasi segala kesulitan yang muncul setiap hari, dengan meningkatkan resiliensi, maka individu akan mampu untuk mengatasi kesulitan apapun yang muncul di dalam kehidupan. Wasoga dkk dalam Moleli (2005) Mahasiswa yang memiliki resiliensi tinggi, maka mereka dapat berfungsi dengan baik dalam mengatasi segala tantangan yang ada di lingkungan untuk mencapai kesuksesan akademis. Mahasiswa yang memiliki resiliensitinggidapatmemandang penderitaan sebagai tantangan, kegagalan sebagai awal keberhasilan, dan keputusasaan menjadi kekuatan. Individu yang memiliki resiliensi terdorong untuk berkembang dan menjadi lebih baik. resiliensi juga bisa memberikan sebuah kekuatan kepada mahasiswa untuk

\footnotetext{
${ }^{1}$ Mahasiswa Program Studi Bimbingan dan Konseling FIP UNJ, noviifitriani@gmail.com

${ }^{2}$ Dosen Program Studi Bimbingan dan Konseling FIP UNJ, wahyuni.eka@gmail.com

${ }^{3}$ Dosen Program Studi Bimbingan dan Konseling FIP UNJ, happykarlina.unj2005@gmail.com
} 
melawan kesulitan-kesulitan atau tantangantantangan mahasiswa untuk meraih prestasi akademik. Namun, mahasiswa dengan resiliensi rendah sangat mungkin untuk tidak mampu menyesuaikan diri dan beradaptasi terhadap perubahan, tuntutan dalam perkuliahan, dan kekecewaan yang muncul dalam kehidupan. Hal tersebut juga dikatakan oleh Suwarjo (2008) bahwa seseorang dengan tingkat resiliensi yang rendah tidak akan mampu menilai, mengatasi, dan meningkatkan diri ataupun mengubah dirinya dari keterpurukan atau kesengsaraan dalam hidup. Peneliti melakukan studi pendahuluan dengan angket kepada mahasiswa FIP angkatan 2013-2014 yang memiliki IP $\leq 2.5$, hasil studi pendahuluan yang telah dilakukan yaitu mahasiswa tidak memiliki hubungan dekat dengan teman di kampus, mahasiswa mudah menyerah ketika terjadi kesulitan dalam perkuliahan sehingga jarang datang untuk mengikuti perkuliahan. Akibatnya tertinggal materi yang disampaikan oleh dosen dan tidak mengerjakan tugas-tugas perkuliahan. Mahasiswa merasa banyak tuntutan yang diterima untuk menunjang prestasi akademiknya. Berdasarkan Pedoman Akademik Universitas Negeri Jakarta (2011) tuntutan dalam perkuliahan seperti kegiatan tatap muka, tugas terstruktur, kehadiran dalam perkuliahan, praktikum, tata tertib mengikuti perkuliahan, dan ujian.

Berdasarkan data tersebut, maka perlu untuk dilakukan intervensi, agar mahasiswa mampu untuk menghadapi tuntutan maupun kesulitan yang akan dihadapi selama perkuliahan. Jika tidak di intervensi, mahasiswa mungkin akan mudah putus asa dan menyerah sebelum menghadapi kesulitan-kesulitan, terus merasa cemas, takut dan menghindar dari tuntutan dalam perkuliahan. Mahasiswa yang memiliki resiliensi rendah (FDP) diharapkan memiliki tekad yang kuat, komitmen, memiliki kepercayaan diri, mampu bekerja keras, dapat mengatasi kesulitan-kesulitan dalam hidup dan juga dapat merubah cara berpikir dan mengatasi masalahnya untuk mencapai tujuan hidupnya, sehingga dalam penelitian ini akan dilakukan konseling individual dengan pendekatan Rational Emotive Behavioral Therapy (REBT). Pendekatan konseling, salah satu teori atau pendekatan yang dianggap sesuai untuk meningkatkan resiliensi yaitu Pendekatan REBT (Rational Emotive Behaviour Therapy), dicetuskan pertama kali oleh psikolog bernama Albert Ellis. Sedangkan teknik yang akan digunakan adalah dispute kognitif (cognitive disputation). Dispute cognitive adalah teknik untuk mengubah keyakinan irasional menjadi keyakinan rasional. Salah satu bentuk keyakinan irasional yang diidentifikasi oleh Albert Ellis (1979) adalah lari dari kesulitan dan tanggung jawab lebih mudah daripada menghadapinya. Neenan (2009) mengatakan bahwa Konseling Rational Emotive Behavior Therapy dianggap sebagai salah satu pendekatan yang sesuai untuk meningkatkan resiliensi remaja maupun dewasa, berdasarkan atas asumsi bahwa proses pengembangan resiliensi melibatkan kinerja dari aspek kognitif, emosi dan perilaku dalam diri individu, sehingga konseling Rational Emotive Behavior Therapy dan teori ABC di dalamnya dianggap tepat. Tingkat resiliensi yang rendah dalam diri individu akan menyebabkan kerentanan terhadap berbagai jenis faktor risiko, kerentanan tersebut akan memunculkan perasaan dan perilaku yang disfungsional atau merusak diri. Perasaan dan perilaku disfungsional sangat berkorelasi dengan 'keyakinan irasional' (irrational beliefs). Ellis \& Harper dalam Huchinson dan Chapman (2010) Konseling Rational Emotive Behavior Therapy mengajari individu tentang bagaimana menghilangkan keyakinan irasional dan menggantinya dengan keyakinan rasional untuk mengubah perasaan dan perilaku individu menjadi lebih baik dan lebih fungsional. Resiliensi berkaitan dengan keyakinan irasional, mahasiswa memiliki keyakinan irasional artinya tidak dapat berpikir ilmiah, yaitu mahasiswa menganggap masalah bukan sebagai tantangan dalam hidupnya yang harus di hadapi dengan baik. Penelitian tentang resiliensi menggunakan pendekatan 
REBT pernah dilakukan, salah satunya oleh Mashudi (2012) yang menunjukkan hasil penelitian secara empirik bahwa intervensi konseling Rational Emotive Behavior teruji efektif untuk meningkatkan resiliensi pada siswa SMKN 9 Bandung. American Psychiatric Association, 1994 dalam Dryden (2003) Teknik REBT membuktikan efektifitas dalam menangani perilaku remaja maupun dewasa, yaitu kemampuan seseorang ketika menghadapi situasi yang sulit atau masalah dalam hidupnya. Artinya bahwa, pendekatan konseling REBT ini efektif dalam menangani perilaku atau masalah pada usia dewasa yaitu mahasiswa.

\section{KAJIAN TEORI RESILIENSI}

$$
\text { Reivich dan Shatté (2002) }
$$

menjelaskan resiliensi merupakan kemampuan untuk bertahan, bangkit dan menyesuaikan dalam situasi atau kondisi yang sulit. Mahasiswa resilien tahu bagaimana ia harus menghadapi suatu masalah dan dapat menemukan cara penyelesaiannya. Resiliensi adalah kemampuan manusia untuk menghadapi dan mengatasi rintangan atau kesulitan dalam hidup sehingga individu tersebut menjadi lebih kuat. Reivich dan Shatté (2002) mengatakan bahwa ada tujuh kemampuan yang dapat dijadikan untuk membentuk tingkat resiliensi. Tujuh kemampuan tersebut antara lain:

1. Regulasi emosi

Regulasi emosi merupakan kemampuan mahasiswa untuk tetap tenang ketika menghadapi suatu masalah. Kemampuan regulasi penting untuk menjalin hubungan interpersonal, kesuksesan kerja dan menjaga kesehatan fisik. Mahasiswa yang kurang mampu mengendalikan emosinya akan sulit membangun dan memelihara persahabatan sehingga akan cenderung mengatasi konflik dengan cara emosional.

2. Kontrol Impuls

Kemampuan mengendalikan dorongan merupakan kemampuan mahasiswa untuk mengatur dorongan dalam dirinya, sehingga tidak mudah lepas kendali. Mahasiswa resilien lebih mampu menunda pemuasan, memilki hubungan sosial dan kemampuan akademik lebih baik. Regulasi emosi dan mengendalikan dorongan berhubungan erat, yaitu mahasiswa yang kuat dalam mengendalikan dorongan cenderung tinggi dalam regulasi emosi, sehingga mengarahkan pada perilaku resiliensi.

3. Optimisme

Optimisme merupakan kemampuan penting yang harus dimiliki oleh mahasiswa resilien. Optimisme adalah ketika melihat bahwa masa depan cemerlang. Optimisme yang dimiliki oleh seorang mahasiswa menandakan bahwa mahasiswa tersebut percaya bahwa dirinya memiliki kemampuan untuk mengatasi kemalangan yang mungkin terjadi di masa depan.

4. Kemampuan Menganalisis Masalah

Kemampuan menganalisis masalah merupakan istilah yang digunakan untuk merujuk pada kemampuan individu untuk mengidentifikasi penyebabpenyebab dari permasalahan mereka. Jika mahasiswa tidak mampu memperkirakan penyebab dari permasalahan secara akurat, maka mahasiswa tersebut akan membuat kesalahan sama.

5. Empati

Empati sangat erat kaitannya dengan kemampuan individu untuk membaca tanda-tanda kondisi emosional dan psikologis orang lain. Ketidakmampuan berempati berpotensi menimbulkan kesulitan dalam hubungan sosial.

6. Efikasi Diri

Efikasi diri menggambarkan keyakinan mahasiswa bahwa ia dapat memecahkan masalah yang dialami dan keyakinan mahasiswa terhadap kemampuannya untuk mencapai kesuksesan. Mahasiswa resilien memandang masalah adalah tantangan dalam hidup, dan percaya diri mampu mengatasi dan menyelesaikan masalah yang akan terjadi. 
7. Pencapaian

Pencapaian yaitu kemampuan individu meraih aspek positif atau hikmah dari kehidupan setelah menimpa kemalangan. Kemampuan mahasiswa untuk berani mengatasi segala ketakutan-ketakutan yang mengancam dalam kehidupan.

\section{RATIONAL EMOTIVE BEHAVIOUR THERAPY (REBT)}

Menurut Albert Ellis dan Windy Dryden (2007) Pendekatan Rational Emotive Behavioral Therapy (REBT) merupakan pendekatan yang mengubah pemikiran irasional konseli menjadi pemikiran rasional, sehingga mempengaruhi perubahan tingkah laku pada konseli menjadi lebih baik. Rational Emotive Behavioral Therapy (REBT) merupakan pendekatan kognitifbehavioral. Fokus proses konseling dari pendekatan ini adalah tingkah laku, tetapi terdapat penekanan bahwa tingkah laku yang bermasalah itu disebabkan oleh pemikiran yang irasional sehingga fokus penekanannya adalah mengenai pemikiran individu. Albert Ellis menambahkan kata behavior dalam pendekatan ini karena menurutnya, tingkah laku selalu dipengaruhi oleh pikiran dan perasaan (Ellis \& Dryden, 2007). Tujuan dari konseling Rational Emotive Behavioral Therapy (REBT) adalah membantu konseli untuk melihat kesalahan berpikirnya dan lebih mengembangkan pemikiran rasional. Selain itu juga mengembangkan tingkah laku yang lebih baik dan meningkatkan keterampilan pribadi sosial konseli.

\section{METODE PENELITIAN}

Tujuan penelitian untuk mengetahui adanya peningkatan resiliensi dengan menggunakan teknik dispute cognitive dari pendekatan Rational Emotive Behaviour Therapy (REBT) pada mahasiswa yang memiliki resiliensi rendah di Fakultas Ilmu Pendidikan Universitas Negeri Jakarta. Penelitian ini dilakukan pada Mahasiswa Psikologi Angkatan 2014 yang memiliki resiliensi rendah. Penelitian dilakukan pada bulan April-Desember 2015. Dilakukan tiga belas kali pertemuan kegiatan konseling individu dengan pemberian baseline (A) dan intervensi (B). Kegiatan dilakukan di gedung Daksinapati lantai 2 yaitu Di Lab. Konseling. Metode yang digunakan dalam penelitian adalah Single Subject Research (SSR), dengan desain A-B. Teknik yang digunakan dalam penelitian adalah purposive sampling karena hanya mahasiswa yang memiliki resiliensi rendah yang menjadi subjek penelitian berinisial FDP. Penelitian menggunakan instrumen adaptasi dari teori Reivich dan Shatte (2002) yaitu "Resilience Quotient (RQ Test)" menggunakan skala Likert. Peneliti menggunakan instrumen RQ Test setiap pertemuan, karena penelitian ini menggunakan SSR dengan desain A-B dan termasuk dalam perilaku covert (tidak bisa diamati langsung). Heppner (2008) mengatakan bahwa hasil dari pengisian instrumen yang telah dilakukan lebih dari sekali akan menyebabkan peningkatan karena telah ingat dengan butir pernyataan, tanggapan sebelumnya, dan sebagainya, sehingga peneliti mengantisipasi agar tidak terjadi hal tersebut, yaitu dengan cara menggunakan tampilan instrumen yang berbeda pada saat baseline dan intervensi, dan pernyataan butir dilakukan secara acak setiap kali pemberian instrumen.

Peneliti melakukan uji coba instrumen pada 15 responden yaitu mahasiswa yang memiliki IP $\leq 2.5$ didapat 44 yang valid dan 12 item yang drop. Sedangkan berdasarkan rumus alpha cronbach didapat nilai reliabilitas sebesar 0,774. Menurut Arikunto (2010) dilihat dari tabel interpretasi nilai reliabilitas yang berarti cukup, artinya instrumen resiliensi Resilience Quotient (RQ Test) reliabel dan layak digunakan sebagai alat ukur dalam penelitian. Berdasarkan pemaparan dalam latar belakang masalah, maka peneliti menganggap pentin untuk melakukan penelitian tentang penerapan teknik dispute coginitive dalam pendekatan Rational Emotive Behavior Therapy (REBT) untuk meningkatkan resiliensi mahasiswa Program Studi Psikologi Fakultas Ilmu 
Pendidikan Universitas Negeri Jakarta.

\section{HASIL DAN PEMBAHASAN}

Penelitian dilakukan sebanyak tiga belas kali pertemuan. Pertemuan pertama sampai dengan pertemuan keempat, peneliti melakukan baseline (A) untuk memperoleh data skor awal resiliensi sebelum diberikan intervensi. Pada pertemuan kelima peneliti mulai melakukan intervensi(B) karenakondisi baseline sudah stabil. Menurut Juang (2005) keadaan data stabil pada kondisi baseline secara meyakinkan bahwa intervensi perlu segera diberikan. Pada pertemuan kelima yaitu tahap awal yang dilakukan sebanyak dua kali. Pada tahap awal pertemuan ke lima peneliti membangun aliansi kerja, dan pertemuan ke enam mengajarkan teori $\mathrm{ABC}$, lalu pada pertemuan selanjutnya tahap tengah dilakukan sebanyak empat kali pertemuan, Pertemuan ke tujuh yaitu mengidentifikasi keyakinan irasional melalui analisis $\mathrm{ABC}$, analisa $\mathrm{ABC}$ berdasarkan asesmen, pencetus (antecedent " $A$ ") yang berasal dari dalam diri dan luar diri.

Pencetus yang berasal dari dalam diri yaitu mata kuliah yang sulit dipahami, tidak dapat mengatur waktu belajar, tidak suka dengan dosen, ketidaksiapan diri dalam menghadapi ujian, presentasi, tugas/kuis, merasa tidak mampu untuk melanjutkan beasiswa bidikmisi, sedangkan pencetus yang berasal dari luardiriyaitu banyaktugas, banyak mengikuti kegiatan di kampus seperti acara psikologi expo, magnetic, brainstorming, dan festival akademik, dosen yang tidak adil memberikan nilai, tetapi FDP memiliki sikap positif yaitu memiliki motivasi untuk bisa meningkatkan IP sehingga dapat melanjutkan beasiswa bidikmisi sampai dengan selesai. Berdasarkan pencetus (antecedent) tersebut, FDP memiliki keyakinan (Belief "B") bahwa materi yang didapatkan dari dosen tidak jelas, IP jelek karena dosen, hal ini termasuk dalam bentuk keyakinan irasional yang telah dikatakan oleh Ellis dalam Gladding (1992) yaitu lari dari kesulitan dan tanggung jawab lebih mudah daripada menghadapinya. Konsekuensi (Consequence "C") yang diterima oleh FDP yaitu merasa ketakutan ketika dosen memberikan hasil penilaian yang tidak adil, cemas ketika ada penugasan, kuis atau pun ujian dan FDP menarik diri ketika di dalam kelas seperti tidak turut aktif dalam kegiatan kelompok, dan konsekuensinya dapat merugikan FDP. Selanjutnya pertemuan ke delapan dan ke sembilan peneliti menginternalisasikan keyakinan rasional baru dengan menggunakan teknik dispute cognitive dengan mengajukan 3 (tiga) jenis pertanyaan dispute yaitu, dispute logis, reality testing, dan pragmatic disputation, dan pertemuan ke sepuluh dan sebelas peneliti meningkatkan setiap aspek resiliensi FDP. Pada pertemuan selanjutnya tahap akhir dilakukan sebanyak dua kali pertemuan yaitu pertemuan ke dua belas melakukan evaluasi. Pada tahap evaluasi ini FDP melakukan analisis $\mathrm{ABC}$ yang kedua setelah diberikan treatment. Tujuannya yaitu peneliti memastikan bahwa FDP mencapai perubahan yang signifikan dalam berpikir, perubahan tersebut bukan disebabkan oleh faktor lain. Pada pertemuan ke tiga belas melakukan penutup, yaitu peneliti bersama FDP menyimpulkan kegiatan selama sesi konseling berlangsung dan peneliti meminta FDP untuk menyebutkan manfaat dari sesi konseling yaitu sudah memahami tentang resiliensi, dapat mendorong diri sendiri untuk mengubah hal negative, perasaan FDP lebih tenang dalam menjalani tuntutan perkuliahan, FDP mengutarakan bahwa selama melakukan sesi konseling sangat merasakan manfaat untuk dirinya yang memiliki resiliensi rendah sehingga resiliensi FDP dapat meningkat. Adapun peningkatan skor resiliensi adalah sebagai berikut:

Grafik 1

Peningkatan Skor Resiliensi 


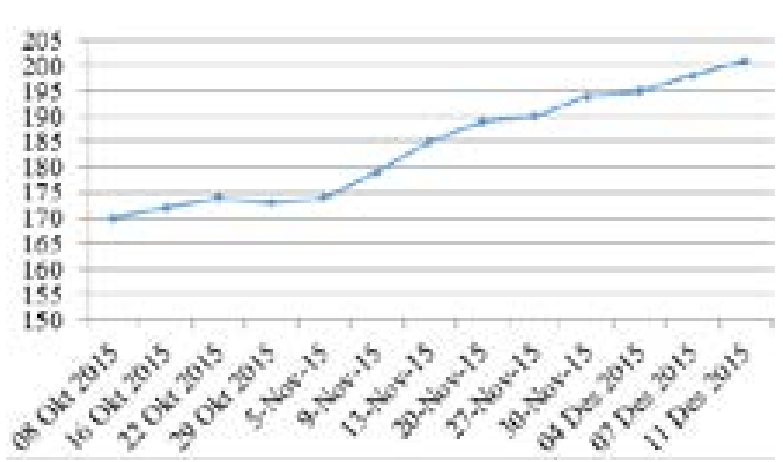

Tabel 1

Hasil Skor Resiliensi

\begin{tabular}{|c|c|c|c|c|c|c|c|}
\hline \multirow[b]{2}{*}{$\begin{array}{l}\widetilde{\widetilde{J}} \\
\text { D. } \\
\stackrel{0}{\Xi} \\
\mathbb{E}\end{array}$} & \multirow[b]{2}{*}{ 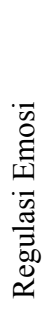 } & \multirow[b]{2}{*}{ 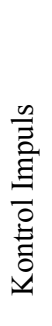 } & \multicolumn{3}{|c|}{ Skor Resiliensi } & \multirow[b]{2}{*}{ 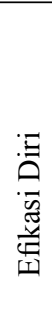 } & \multirow[b]{2}{*}{ 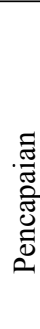 } \\
\hline & & & 泀 & 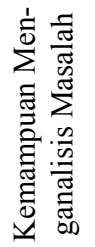 & 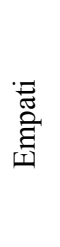 & & \\
\hline $5 \mathrm{Nov}$ & 5 & 2 & 3 & 3 & 4 & 3 & 4 \\
\hline $9 \mathrm{Nov}$ & 6 & 2 & 3 & 2 & 4 & 3 & 5 \\
\hline $13 \mathrm{Nov}$ & 6 & 2 & 2 & 4 & 5 & 5 & 5 \\
\hline $20 \mathrm{Nov}$ & 8 & 3 & 4 & 4 & 6 & 6 & 6 \\
\hline $27 \mathrm{Nov}$ & 8 & 5 & 7 & 6 & 6 & 7 & 7 \\
\hline $30 \mathrm{Nov}$ & 10 & 6 & 8 & 7 & 7 & 8 & 8 \\
\hline 4 Des & 11 & 8 & 9 & 8 & 8 & 11 & 9 \\
\hline 7 Des & 12 & 10 & 10 & 9 & 9 & 12 & 11 \\
\hline 11 Des & 14 & 12 & 12 & 13 & 13 & 13 & 12 \\
\hline
\end{tabular}

Berdasarkan tabel 1 dapat dilihat bahwa resiliensi FDP meningkat setelah diberikan treatment dengan teknik dispute cognitive. Pada aspek regulasi emosi skor FDP sebesar 5 saat diberikan intervensi awal dan meningkat mencapai skor sebesar 14 saat diberikan intervensi akhir. Pada aspek kontrol impuls skor FDP sebesar 2 saat diberikan intervensi awal dan meningkat mencapai skor sebesar 12 saat diberikan intervensi akhir. Pada aspek optimis skor FDP sebesar 3 saat diberikan intervensi awal dan meningkat mencapai skor sebesar 12 saat diberikan intervensi akhir. Pada aspek kemampuan menganalisis masalah skor FDP sebesar 3 saat diberikan intervensi awal dan meningkat mencapai skor sebesar 13 saat diberikan intervensi akhir. Pada aspek empati skor FDP sebesar 4 saat diberikan intervensi awal dan meningkat mencapai skor sebesar 13 saat diberikan intervensi akhir. Pada aspek efikasi diri skor FDP sebesar 3 saat diberikan intervensi awal dan meningkat mencapai skor sebesar 13 saat diberikan intervensi akhir. Pada aspek pencapaian skor FDP sebesar 4 saat diberikan intervensi awal dan meningkat mencapai skor sebesar 12 saat diberikan intervensi akhir. 


\section{KESIMPULAN DAN SARAN}

Setelah semua tahap dalam penelitian dilakukan, dapat disimpulkan bahwa penelitian yang telah dilakukan yaitu konseling rasional emotif behavioral dengan menggunakan teknik dispute cognitive untuk meningkatkan resiliensi, hasil penelitian resiliensi FDP meningkat. Hasil perhitungan skor resiliensi sebelum diberikan intervensi dengan menggunakan teknik dispute cognitive yaitu skor resiliensi FDP berjumlah 170 berada pada kategori rendah dan setelah diberikan intervensi terdapat peningkatan skor resiliensi menjadi 201 berada pada kategori sedang. Penggunaan teknik tersebut didasarkan atas penelitian terdahulu, menunjukkan keberhasilan teknik kognitif dalam meningkatkan resiliensi.

Saran-saran yang dapat menjadi pertimbangan berdasarkan hasil penelitian adalah sebagai berikut:

1. Bagi Mahasiswa

Mempersiapkan diri sebaik mungkin untuk menghadapi tuntutan dalam perkuliahan yang ada di Perguruan Tinggi, dan Mahasiswa dapat mengembangkan resiliensi karena resiliensi penting untuk keberhasilan akademik.

2. Bagi Calon Konselor

Menggunakan teknik dispute cognitive untuk meningkatkan individu yang memiliki resiliensi rendah.

3. Bagi UPT-LBK

Mengumpulkan dan membentuk suatu layanan konseling kelompok pada mahasiswa yang memiliki resiliensi rendah agar dapat mengatasi kesulitan atau hambatan yang terjadi pada dirinya, terutama ketika menjalani tuntutan perkuliahan.

4. Bagi peneliti selanjutnya

Hasil penelitian dapat digunakan sebagai rujukan penelitian relevan dengan judul penerapan teknik dispute cognitive dalam pendekatan REBT untuk meningkatkan resiliensi, peneliti selanjutnya dapat memilih teknik konseling dalam REBT seperti teknik behavioral, Imajery untuk meningkatkan resiliensi.

\section{DAFTAR PUSTAKA}

Anesty, E, M. (2012). Konseling Rasional Emotif Behavioral Untuk Meningkatkan Resiliensi Remaja. Thesis. UPI: Tidak diterbitkan.

Ellis, A. \& Dryden, W. (2007). The Practice of Rational Emotive Behavior Therapy (2nd ed.). Berlin: Springer.

Dryden, W. (2003). The REBT pocket companion for clients. New York: Albert Ellis Institute.

Gladding, S.T. (1992). Counseling a comprehensive profession, 2nd ed. New York: Maxwel MacMilan International.

Grothberg, E. (1999). Tapping Your Inner Strength. Oakland: New Harbinger Publication.

Heppner \& Bruce E. (2008). Wampold dan Denis M. Kivlinghan, Research Design in Counseling (3rd ed.). Belmont: Thomson Learning.

Moleli, F. (2005). Protective factors that could foster resilience in first year students. Masters Mini-thesis. Education Faculty, University of the Western Cape: Bellville.

Neenan \& Dryden, W. (2004). Rational Emotive Behaviour Therapy in action. London: New Delhi.

Neenan, Michael. (2009). Developing Resilience, A Cognitive Behavioral Approach. New York: Routledge.

Reivich \& Shatté, A. (2002). The Resilience Factor: 7 essential Skills for Overcoming Life's Inevitable Obstacles. New York: Broadway Books.

Suharsimi, A. (2010). Manajemen Penelitian. Jakarta: Rineka Cipta.

Sunanto, J. (2005). Pengantar Penelitian dengan Subyek Tunggal. CRICED University of Tsukuba. 
Suwarjo. (2008). Model Konseling Teman Sebaya untuk Pengembangan Daya Lentur (Resilience): Studi Pengembangan Model Konseling Teman Sebaya untuk Mengembangkan Daya Lentur Remaja Panti Sosial Asuhan Anak Propinsi Daerah Istimewa Yogyakarta. Disertasi. UPI. Tidak Diterbitkan 